\title{
La traducción deficiente, del inglés al español, de obras teóricas sobre las organizaciones: Un obstáculo al conocimiento ${ }^{* 1}$
}

Jorge Ríos Szalay Investigador, División de Investigación, Facultad de Contaduría y Administración, UNAM jrszalay@gmail.com

* Este trabajo es uno de los productos de una estancia sabática del autor en la Universidad de Quebec en Montreal, realizada gracias a una beca del Programa PASPA, que recibió para el efecto de la UNAM a través de su Dirección General de Asuntos del Personal Académico.

${ }^{1}$ Una primera versión de una parte de este trabajo se presentó en el XI Foro de Investigación: Congreso Internacional de Contaduría, Administración e Informática, Facultad de Contaduría y Administración, Universidad Nacional Autónoma de México, México, D. F., octubre 25-27, 2006, con el título "Deficiencias de traducción de obras de administración del inglés al español: reflexiones sobre un obstáculo al conocimiento".

\section{Resumen}

En este artículo se argumenta en primer lugar que el lenguaje es elemento vital del método de la ciencia, toda vez que el conocimiento se crea a través del diálogo establecido entre los investigadores fundamentalmente por medio de la palabra escrita, por lo que el rigor o descuido que se tenga en su uso influye en el conocimiento mismo. Consecuentemente, se destaca que la traducción del pensamiento de un autor de una lengua a otra es un asunto de la mayor importancia, puesto que puede ser un medio para el avance o para la obstrucción del conocimiento. En segundo término, y como parte central, se argumenta que a menudo las traslaciones de libros de administración y de teoría de la organización del inglés al español son tan deficientes que distorsionan ideas importantes de sus autores, y se ofrecen evidencias de ello a través del análisis de las traducciones de pasajes particularmente importantes de la obra de cinco influyentes pensadores: Harold Koontz y Cyril O' Donnell, George Terry, Chester Barnard y Nicos Mouzelis. Finalmente, se analizan en forma somera las principales causas de esta problemática y se esbozan algunas ideas preliminares acerca de lo que se podría hacer con vistas a atenuarla.

Palabras clave: lenguaje de la administración, lenguaje de la teoría de la organización, terminología de la administración, traducción y ciencia. 


\title{
Deficient translations, from english to spanish, of theoretical books on organizations: an obstacle to knowledge
}

\begin{abstract}
Firstly, it is argued that language is a vital element of the scientific method since knowledge is created through the dialog established between researchers mainly by means of written words; therefore, the rigor or negligence when using language influences knowledge itself. Consequently, translation of an author's thought from one language to another is a crucial issue since it may function as a mean for advancing or for obstructing knowledge. Secondly, it is argued that translations from English to Spanish of management and theory of organization books are often so mistaken that they distort important ideas of the authors. Evidences of this assertion are presented through analyzing the translation of important paragraphs of books of five influential thinkers: Koontz and O'Donnell, Terry, Barnard and Mouzelis. Finally, main causes of these problems are briefly analyzed and some preliminary ideas to diminish them are outlined.
\end{abstract}

Keywords: management language, theory of organization language, management terminology, translation and science.

[...] las oraciones son pequeños discursos tomados de discursos más largos que son los textos. Los traductores lo saben bien: son textos y no oraciones, no palabras, lo que nuestros textos quieren traducir. Y los textos a su vez forman parte de conjuntos culturales a través de los cuales se expresan visiones del mundo diferentes [...]

Paul Ricoeur (2005:63)

\section{Introducción}

El correcto uso del lenguaje es una variable de mucho mayor importancia en la generación y desarrollo del conocimiento científico que la atención que se le suele prestar en algunos círculos académicos; las traducciones de textos de una lengua a otra, fieles servidoras o traidoras subrepticias del pensamiento de infinidad de autores, juegan un papel trascendente, positivo o negativo, en dichos procesos. La ciencia se expresa y avanza a través del lenguaje escrito. Bien dice Silva: "La ciencia es teoría. [...] Toda teoría es un texto" (2004:16). Únicamente mediante 
el lenguaje escrito es posible alimentarse cabalmente del pensamiento de otros, crear teorías y comunicarlas a otros especialistas para su examen crítico. Es pues a través de este diálogo que entablan los pensadores entre sí, sin límites de tiempo y espacio, que se hace posible la expansión de las fronteras del conocimiento.

Gutiérrez Rodilla, en su obra La ciencia empieza en la palabra (1998), argumenta que el discurso o lenguaje científico tiende, entre otras, hacia tres metas: precisión, neutralidad y concisión o economía. La primera, la cualidad más importante, está relacionada en buena medida con la precisión de los términos empleados y peligra en la medida en que sean mayores la sinonimia (i.e., la existencia de dos o más términos para referirse a un mismo concepto) y la polisemia (i.e., la existencia de varios significados para un solo concepto) que contengan esos términos ${ }^{2}$. Evidentemente, las traducciones incorrectas obran en contra de la precisión a la que aspira el lenguaje científico. Ello puede suceder por varias razones. Quizás la más común se da cuando por no conocer la disciplina o el área a la que pertenece la obra bajo traducción el encargado de realizarla interpreta erróneamente el texto y por consiguiente cae en imprecisiones, si no es que en graves tergiversaciones. Otro caso frecuente se presenta cuando por desconocimiento del área académica correspondiente y de su terminología el traductor crea un neologismo para designar un concepto para el cual ya existía un término generalmente aceptado, agregando así un sinónimo innecesario del mismo que propicia confusión ${ }^{3}$. Igualmente sucede cuando por negligencia o falta de dominio del idioma de llegada el traductor no selecciona las palabras que traduzcan con precisión, sino sólo aproximadamente, cierta idea del texto original, a pesar de haberla interpretado correctamente.

\footnotetext{
${ }^{2}$ De conformidad con la terminología — campo del conocimiento originalmente surgido como rama de la lingüística y hoy una disciplina autónoma con importantes vínculos con las ciencias cognitivas principalmente- entendemos por término — también llamado término científico, término científico-técnico, término especializado o tecnicismo - una palabra (ya sea sustantivo, verbo, adverbio o adjetivo) o conjunto de palabras, que denomina o nombra un concepto (Gutiérrez Rodilla, 1998; Wüster, 1998 y Cabré, 1999). Así, por ejemplo, son términos administrativos los sustantivos dirección, autoridad lineal y tramo de control, lo mismo que los verbos presupuestar y organizar y los adjetivos ineficiente y competitivo. Asimismo, conviene aclarar que el vocablo terminología tiene tres acepciones: una es la que se refiere a la disciplina que estudia los términos científicotécnicos; otra es la que designa al conjunto de directrices o principios que rigen la recopilación de términos con fines de normalización, difusión, etc.; la tercera es la que denomina al conjunto de términos de una disciplina, por ejemplo, la terminología de la sociología, la de la física cuántica o la de la administración (Cabré, 1999; Gutiérrez Rodilla, 1998). La acepción que utilicemos en cada caso a lo largo de este trabajo se podrá entender fácilmente por el contexto en que se use.

${ }^{3}$ Gutiérrez Rodilla clasifica la neología desde el punto de vista de su intencionalidad en voluntaria e involuntaria. El caso que acabamos de referir podemos ubicarlo claramente en esta última (1998).
} 
Esta misma lingüista nos hace notar que el lenguaje y el pensamiento científicos se necesitan mutuamente y nos advierte con claridad acerca de los escollos que puede significar para el progreso de la ciencia el empleo de un lenguaje deficiente. Tras argumentar que el lenguaje científico influye en el pensamiento, en la elaboración de las hipótesis y en las clasificaciones de la ciencia, condicionándolas, afirma "Incluso puede suceder que el lenguaje juegue en contra del avance en la solución de los problemas de la ciencia: la existencia de una mala terminología, de un lenguaje científico erróneo puede obligar a cambiar los conceptos, haciéndolos, de esta forma, erróneos también, y a buscar explicaciones ad hoc, lo que va en contra del rigor científico" (Gutiérrez, 1998: 25). Y en seguida apoya su aserción con la siguiente cita por demás ilustrativa, particularmente porque el uso deficiente del lenguaje que ejemplifica deriva precisamente de una incorrecta traducción:

Existe en nuestro organismo un lugar anatómico llamado Prensa de Herófilo (cónfluens sínuum $)^{4}$, que ha tomado el nombre de Herófilo de Calcedonia (s.III a.C.), médico que lo describió por vez primera; sin embargo, él lo había llamado lenós, palabra griega que significa 'cuba' o 'tonel', objetos a los que le recordaría ese lugar en que se origina una gran colección venosa, y con esa forma. Cuando Avicena leyó el lenós de Herófilo no lo tradujo al árabe por "tonel” o "”cuba", sino por el equivalente a otro significado que tiene también la palabra lenós, el de prensa o lagar, es decir, por al-maçára ("almazara"). Posteriormente Gerardo de Cremona, el traductor del Qanum de Avicena al latín, tradujo al-maçára por tórcular, "lagar o prensa", y así, durante mucho tiempo anatomistas y fisiólogos se dedicaron a explicar que en la "prensa de Herófilo" se produce una presión muy fuerte de unas columnas de sangre contra otras y a discutir entre ellos cómo se llevaba a cabo esta función de prensa, función totalmente inexistente; pero una vez inventada la expresión, había que darle una explicación adecuada (Barcia,1980: 380, citado por Gutiérrez, 1998: 25).

Inmediatamente después de la cita, Gutiérrez hace una deducción a partir de sus argumentos previos que nos parece, además de acertada, pertinente para destacar el importante rol que desempeña el lenguaje - y por ende su correcta traducción - en el desarrollo del conocimiento científico: "De lo anterior debemos deducir que el lenguaje es una parte ineludible de la metodología de la ciencia pues, no sólo describe lo que el científico hace, sino que puede contribuir a determinarlo" (1998: 25-26).

\footnotetext{
${ }^{4}$ Ocho de los nueve vocablos en latín, griego o árabe de esta cita aparecen en el original con acento ortográfico, motivo por el cual merecían que les hubiéramos adherido la leyenda sic entre paréntesis en cada caso. Sin embargo, hemos preferido no hacerlo y anotar en su lugar una sola aclaración, la presente, a fin de permitir una lectura más fluida del pasaje.
} 
Debiera ser claro pues que el diálogo entre investigadores establecido vía el lenguaje escrito se ve seriamente obstaculizado, y con ello obstruida la divulgación y el desarrollo del conocimiento, cuando la traducción de las ideas de su lengua nativa a otra tergiversa el pensamiento de su autor. Pero, ¿atañe esto a las disciplinas que estudian las organizaciones?, ¿existen errores de traducción de obras importantes de ellas? Si los hay, ¿son lo suficientemente graves como para merecer nuestra atención?, ¿qué los podría estar provocando? y ¿qué se podría hacer para eliminar o reducir sus causas? Dedicaremos las siguientes secciones a tratar de ofrecer una primera respuesta a estas interrogantes

A lo largo de los años en que hemos leído obras teóricas sobre organizaciones en nuestra lengua pero originalmente escritas en inglés — de administración y teoría de la organización principalmente - hemos encontrado frases y vocablos sin sentido que nos han despertado sospechas de la existencia de errores de traducción en infinidad de pasajes. Tras confirmar en diversidad de casos la existencia de tales equívocos, consultando los textos en su idioma nativo, nos hemos dado a la tarea de indagar más sobre este problema, como parte de una investigación más amplia que estamos realizando acerca del lenguaje teórico sobre las organizaciones. Así, exponemos a continuación avances de nuestras indagaciones sobre las deficiencias de traducción de cuatro libros muy influyentes.

\section{Los desaciertos en las múltiples traducciones de la principal obra de Koontz et al.}

El voluminoso texto que Koontz y O'Donnell publicaron por vez primera en 1955 con el título Principles of Management: An Analysis of Managerial Functions y cuya segunda edición en español (1961) se tradujo como Principios de dirección de empresa: un análisis de las funciones directivas, constituye sin duda la obra más importante de ambos autores, a la vez que se erige como uno de los libros introductorios a la administración más completos y relevantes de la segunda mitad del siglo $\mathrm{XX}^{5}$. Este libro clásico - que ha sido corregido, pulido y actualizado a lo largo de su ya medio siglo de vida, merced al sentido autocrítico de sus

\footnotetext{
${ }^{5}$ A través de su larga existencia el texto ha experimentado cambios en su título tanto en inglés como en español, hasta arribar al actual: Management: A Global Perspective (Administración: una perspectiva global), que ostenta por lo menos desde 1993 y 1994 en inglés y en español, respectivamente. Asimismo, sufrió un cambio de coautor: desde 1955 hasta comienzo de la década de 1980 Harold Koontz y Cyril O'Donnell fueron los autores; a partir de los albores de los años noventa, tras su fallecimiento, O' Donnell es substituido por Heinz Weihrich.
} 
progenitores - ha jugado un importante rol en todo el orbe, particularmente en países latinoamericanos como México, donde contribuyó de manera relevante a la formación de las primeras generaciones de profesionales universitarios de este campo, cuando las obras de administración disponibles en español eran escasas. Como evidencias de la trascendencia de la obra, podemos mencionar que ha sido traducida a 16 idiomas y que los tirajes de sus diversas ediciones y reimpresiones han sido muy amplios; baste ejemplificar que de las ediciones en español décima (1994) y undécima (1998) se tiraron 25,000 y 27,000 ejemplares, respectivamente. Podemos también agregar que entre los libros que dedican un espacio importante al análisis de la teoría administrativa resulta difícil encontrar los que no citen este texto, sobre todo entre los de autores latinoamericanos ${ }^{6}$.

Pues bien, hemos analizado comparativamente, entre sí y con relación a las correspondientes ediciones en inglés, ocho ediciones en español de la referida obra $\left(2^{\mathrm{a}}, 3^{\mathrm{a}}, 4^{\mathrm{a}}, 5^{\mathrm{a}}, 6^{\mathrm{a}}, 10^{\mathrm{a}}, 11^{\mathrm{a}}\right.$ y $12^{\mathrm{a}}$, correspondientes respectivamente a los años 1961 , 1970, 1972, 1977, 1979, 1994, 1998 y 2003), con el objeto de descubrir errores de traducción o bien reencontrar los que habíamos descubierto previamente en el transcurso de los años sin que nos lo hubiéramos propuesto. A continuación presentamos lo que hemos encontrado.

En las seis primeras ediciones ${ }^{7}$ de las ocho revisadas, existen innumerables equivocaciones de traducción, principalmente de términos administrativos científicotécnicos, con el agravante de que algunos de los términos erróneos ni siquiera son empleados consistentemente —ni al interior de una misma edición, ni a lo largo de múltiples ediciones-, incrementando con ello la confusión que de por sí provocan. Examinaremos en seguida algunos casos a manera de ejemplos.

En la quinta edición (1977) se genera un gran embrollo semántico como consecuencia de las incorrectas traducciones de dos términos básicos, span of control y span of management, sobre todo debido a que para traducir el segundo se emplean

\footnotetext{
${ }^{6}$ Como ejemplos, entre muchos otros, de autores importantes estadunidenses que citan la obra referida, podemos mencionar a D. Mc Gregor (1985: 52), J. A. Litterer (1984: 396) y L. J. Kazmier (1974: xix). Entre los latinoamericanos se encuentran B. Kliksberg (1990:16-17, 36 y 38-39), C. Dávila (2001: 309), A. Reyes Ponce (1985: 16, 19, 25, 26, 27 y 15 citas más), I. Chiavenato (1992: 24, 182, 197, 231, 233 y 564), I. Guzmán Valdivia (1974: 115, 133 y 141), J. A. Fernández Arena (1969: 61, 62, 72, 73, 100 y 124) y W. Jiménez Castro (1965: 227, 228 , 244 y 329$)$.

${ }^{7}$ A partir de aquí, al decir "edición" o "ediciones" nos referiremos a ediciones en español, salvo especificación en contrario.
} 
indistintamente nada menos que ocho términos diferentes. Hace unas seis décadas un traductor acuñó adecuadamente el término tramo de control para referirse a span of control; el neologismo se divulgó y logró aceptación generalizada, llegando así a usarse tanto en libros traducidos del inglés como en obras escritas originalmente en español. No obstante, el traductor de la susodicha edición (1977) lo soslayó, empleando en su lugar el confuso término área de control (1977: 260). Es evidente que aquí el traductor, debido a su falta de dominio del tema y su terminología, produjo una neología involuntaria, como la denomina Gutiérrez (1998: 111). Por otra parte, Koontz y O’Donnell proponen desde la primera edición de sus Principles of Management (1955), reiterándolo en las sucesivas ediciones, que se emplee el término span of management — cuya traducción correcta es tramo de administración - en lugar de span of control, "a pesar del extenso uso de este término", en vista de que el tramo de control (es decir, el número de personas que un administrador tiene bajo su mando) concierne a toda la administración y no únicamente al control, que es sólo una de las funciones administrativas (planeación, organización, integración, dirección y control) (1955: 83). A partir de que hacen su propuesta, los autores emplean invariablemente span of management a lo largo del resto de su obra cada vez que desean referirse a lo que todos llaman span of control. Al traducir aquel término el traductor de la edición que nos ocupa (quinta, 1977) no sólo lo hace erradamente, sino que llega al extremo de acuñar y emplear indistintamente ocho términos diferentes, todos erróneos, para el término inglés: amplitud de comando de la administración, área de la administración, amplitud de comando, magnitud de supervisión, área de supervisión, amplitud de supervisión, amplitud de la administración y amplitud de supervisión de la administración (1977: 260-276). Esta gran inconsistencia provoca que el capítulo en el que aparece, dedicado precisamente al estudio del concepto tramo de control, resulte confuso. Es probable que la creación y uso de tantos sinónimos por parte del traductor haya sido originado por su deseo de evitar la repetición de un mismo vocablo en el afán de mostrar un mejor uso de la lengua. Si ésta fue la motivación de su error, esta persona desconoce lo que todo buen traductor sabe por simple sentido común y que la lingüística nos refuerza: que en el lenguaje de las ciencias y las técnicas, en aras de la precisión, se emplea el mismo término para referirse a un concepto, aunque ese término se repita muchas veces en el texto (Gutiérrez Rodilla, 1998). Es decir, se sigue un criterio diferente del que se emplea, en pos de la elegancia discursiva, en el lenguaje ordinario y especialmente en el literario. De hecho, en la búsqueda de dicha precisión, en el lenguaje científico y técnico no es deseable la existencia de sinónimos de los términos, como ya apuntamos en la introducción. Al traductor le hubiera convenido conocer y seguir la recomenda- 
ción de Engels: "un término técnico debe traducirse siempre por una y la misma expresión en el otro idioma" (1985: XVII, citado por Pedro Scaron).

En la sexta edición (1979) del libro objeto de nuestro análisis, el término Program Evaluation and Review Technique (PERT), cuya correcta traducción es Técnica de evaluación y revisión de programas, se tradujo como Evaluación de Programa y Técnica de Revisión, y como Evaluación del Programa y Técnica de Revisión, frases sin sentido, en las páginas 770 y 772 , respectivamente, mientras que en la página 41 se traduce correctamente. Este mismo error aparece ya en la quinta edición (1977: 659 y 661), cuyo traductor fue otro, por lo cual es presumible que el traductor de la sexta lo haya copiado y trasladado desde aquélla ${ }^{8}$. En ninguna de las restantes ediciones analizadas aparece la incorrección.

Por lo concerniente a la inconsistencia en el empleo de los términos, hasta aquí nos hemos referido exclusivamente a aquélla que se da al interior de una misma edición; abordaremos ahora el caso de su uso inconsistente a través de sucesivas ediciones.

Para continuar con el término span of management, cuya traducción inconsistente al interior de la quinta edición vimos previamente, empecemos por señalar que la falla también se presenta a lo largo de las ediciones segunda, tercera, cuarta, sexta y undécima, en las que podemos encontrar en total cinco términos incorrectos más para referirse al concepto, que al sumarse a los ocho de la quinta edición arrojan un gran total de trece términos erróneos para un solo concepto (ver cuadro 1, al final del artículo).

Otro caso de inconsistencia de términos en el curso de diversas ediciones de la obra que nos ocupa es el de las variadas traducciones de staffing, concepto fundamental para el libro, toda vez que se trata de una de las funciones en que Koontz y

\footnotetext{
${ }^{8}$ Esta presunción se basa, además, en los siguientes elementos: 1) la pequeñísima y peculiar diferencia entre "Evaluación de Programa..." y "Evaluación del Programa..." hecha por el traductor de 1977 es usada por el traductor de 1979 para exactamente los mismos pasajes en que la empleó el primero, lo cual es una casualidad sumamente rara, 2) si el traductor de 1979 hubiera querido consultar alguna traducción previa de la misma obra para auxiliarse de ella en ciertos pasajes o palabras que le presentaran alguna dificultad especial o duda, lo más probable es que recurriera a la edición más cercana cronológicamente; la edición en la cual aparece primero el error que suponemos que el traductor de 1979 copió es precisamente la inmediata anterior a la que él escribió. La cuestión de la probable copia por un traductor de una equivocación cometida por otro traductor respecto a la misma obra es importante en la medida en que, de confirmarse, sería un indicio más de la baja calidad de muchos de los traductores inglés-español de las obras de administración, asunto que trataremos páginas adelante.
} 
O’Donnell dividen la administración (planning, organizing, staffing, directing y controlling), división que constituye el pilar central en que se funda su teoría. Pero conviene que antes de analizar tal inconsistencia veamos el significado correcto de staffing y cómo ha sido traducido.

El vocablo inglés staffing es un sustantivo administrativo que significa suministro de personal, ya que proviene del verbo staff, que significa proveer de personal. Staffing no debiera confundirse en este contexto de funciones de la administración - como, al parecer, lo hace Chiavenato- con el sustantivo staff, que se refiere a un tipo de autoridad (la de apoyo o asesoramiento) ${ }^{9}$. Koontz y O'Donnell definen staffing (traducido en la siguiente definición como integración) de la manera que sigue: "La función administrativa de integración se ocupa de dotar de personal a la estructura de la organización a través de una adecuada y efectiva selección, evaluación y desarrollo de las personas que han de ocupar los puestos dentro de la estructura" (1997: 502). Con base en esta definición, consideramos que de las nueve distintas traducciones que se han dado para el concepto staffing las tres siguientes son las más apropiadas: integración de personal, integración, y dotación de personal ${ }^{10}$, pues son las que dan la mejor idea de la esencia de la función; no obstante, en aras de lograr una mayor precisión, estamos a favor de que únicamente se emplee integración de personal o en todo caso su forma abreviada integración, en virtud de que, además de su pertinencia, ambos términos son los más difundidos y aceptados hasta la fecha para designar al concepto en cuestión y de que la proliferación de sinónimos obra en contra de la precisión, como ya hemos observado. En cambio, son desacertadas las traducciones formación de los cuadros (1961: 315 y ss.), desarrollo del personal (1970: 8, 12, 56, 431), personal (1977: VII), "llenar posiciones (staffing)" (1977: 437), "nombramiento de personal (staffing)" (1977: 1), “dotación de personal (staffing)" (1977: 437-441) e integra-

\footnotetext{
${ }^{9}$ Cuando Chiavenato se refiere a los elementos de la administración según Gulick, los enlista de la siguiente manera, colocando entre paréntesis los vocablos en inglés que este autor empleaba para formar el acróstico PosDCORB como recurso mnemotécnico: a) planeamiento (planning), b) organización (organizing), c) asesoría (staffing), d) dirección (directing), e) coordinación (coordinating), f) información (reporting) y g) presupuestación (budgeting). Como se podrá notar, el staffing de Gulick corresponde a la función que según Koontz, O’Donnell y otros se ocupa del suministro permanente de personal adecuado a la organización, no a la función de asesoramiento, como dice el texto de Chiavenato. Sin embargo, debemos hacer notar que el libro de este autor que estamos citando es una traducción al español del original escrito en portugués, idioma natal del autor, por lo que queda latente la posibilidad de que el error lo haya cometido el traductor y no el autor brasileño (1992: 91).

${ }^{10}$ Aunque, cabe aclarar, la última de estas tres traducciones (usada sólo en la quinta edición, de 1977) no aparece tal y como acabamos de escribirla ("dotación de personal”), sino invariablemente como "dotación de personal (staffing)".
} 
ción de los recursos humanos (1979: 80) ${ }^{11}$. Las dos primeras son desatinadas por limitarse a sólo una de las subfunciones que comprende el concepto; personal es incorrecta por no tratarse, gramaticalmente hablando, de una acción, como sucede con las restantes funciones administrativas (planeación, organización, dirección y control), y además por resultar ambigua; "llenar posiciones (staffing)", por tener un sentido mecanicista, como si se tratara de manipular objetos y no de integrar a la organización seres humanos, y adicionalmente por ser ambigua, al grado de que el traductor tuvo que recurrir al extremo de escribir entre paréntesis el término que precisamente pretende traducir; "nombramiento de personal (staffing)", por resultar muy reduccionista, al limitarse a una actividad (contratación) que sólo forma parte de una de las subfunciones (selección) que abarca el concepto, y también por ser ambigua como en el caso anterior; "dotación de personal (staffing)" sería adecuada si no incluyera el paréntesis, sin embargo, en tal caso se trataría de un sinónimo de integración de personal, con la consiguiente desventaja que ya hemos señalado; integración de los recursos humanos también nos parece una traducción desafortunada, principalmente por ser demasiado extensa y por agregar un sinónimo innecesario. Igualmente consideramos desatinado el empleo de la voz inglesa staffing - así, sola y sin traducción al español — que se hace en la quinta edición (1977: 48, 51 y 55).

Como puede observarse en el cuadro 1, al final del artículo, el término staffing no se traduce consistentemente en la quinta edición (1977), puesto que se utilizan cinco diferentes términos para referirse a él -personal, staffing, "dotación de personal (staffing)”, “llenar posiciones (staffing)” y "nombramiento de personal (staffing)” (1977: VII; 51 y 55; 456-457; 437; 1)_, ni en la sexta edición, en la cual se usan tanto integración como integración de los recursos humanos (1979: viii, 78, 80, 499 y 80, respectivamente). En el mismo cuadro se puede igualmente advertir la inconsistencia en su traducción a lo largo de las ediciones segunda, tercera, quinta, sexta y décima, en las que se emplean en total nueve diferentes términos para el concepto, además de utilizarse el término staffing, tal cual, sin traducir y sin ningún vocablo acompañante.

\footnotetext{
${ }^{11}$ Hemos entrecomillado tres de los cinco términos acabados de citar con el fin de hacer notar que los paréntesis que incluyen fueron escritos por el traductor como parte de cada uno de ellos. Asimismo, señalamos, a manera de ejemplo, sólo algunas de las páginas en que aparecen las traducciones de los términos a los que nos estamos refiriendo, con el fin de no entorpecer la lectura. En lo sucesivo seguiremos utilizando tanto el criterio relativo al entrecomillado de los términos mencionados como el concerniente a la ejemplificación de páginas.
} 
Es de hacerse notar que las inconsistencias de traducción que hemos encontrado a lo largo de múltiples ediciones del mismo libro se dan a pesar de que todas han sido publicadas por la misma editorial. La falla muy probablemente ha sido resultado no sólo de la deficiente calidad de los traductores, sino también del hecho de que éstos no han sido conservados, sino cambiados para cada una de las ediciones, como puede verse en el cuadro 2, ubicado justo antes de las referencias bibliográficas.

Como señalamos previamente, los errores de traducción que hemos analizado aquí son sólo una muestra de los innumerables que hemos hallado en seis de las ocho ediciones examinadas de los Principios de administración de Koontz y coautores. Con ayuda del cuadro 1, podemos realizar una contabilización general de aquellos errores analizados cometidos en la traducción de los términos span of control, span of management y staffing. De las ocho ediciones revisadas, el término span of control, cuya traducción correcta es tramo de control, es traducido erróneamente en tres, empleando para ello dos términos (alcance del control y área de control). El concepto span of management es traducido equivocadamente en cuatro ediciones, usándose en total trece términos distintos para referirlo, además del correcto. Staffing aparece erradamente traducido en cinco ediciones mediante un total de siete términos diversos, además de que en una edición (la quinta) en varias ocasiones el término se emplea tal cual, es decir, sin traducir, independientemente de que también se utilizan en la misma edición en forma indistinta otros cuatro términos erróneos para traducirlo.

\section{La tergiversación de un concepto fundamental de Terry}

La versión española de Principles of Management (Principios de administración), de George Terry, es otra obra clásica que también ha sido fundamental en la formación de múltiples generaciones de administradores profesionales en México y en infinidad de otros países y cuya traducción igualmente se encuentra plagada de equivocaciones. Éstas, por consiguiente, han tenido un amplio efecto multiplicador.

Entre las innumerables fallas de traducción que exhibe la obra destaca por su gravedad la siguiente. Está ampliamente difundido que para Terry las funciones fundamentales de la administración o proceso administrativo son planeación, organización, ejecución y control. Pues bien, sucede que el traductor (traduttore, traditore) de la obra citada tradujo equivocadamente como ejecución lo que el autor estadunidense llamó actuating -que realmente significa motivación de las acciones de las personas - para referirse a la función desempeñada por los admi- 
nistradores para impulsar a sus subordinados a realizar su trabajo con entusiasmo (1971: 163-181 y 487-492, principalmente). De manera que lo correcto hubiera sido nombrar a dicha función motivación, o en último caso dirección; esto último en vista de que las subfunciones que según el propio Terry comprende (motivación, orientación y supervisión de los subordinados, comunicación con ellos, etc.) corresponden a lo que la mayoría de los otros autores de la corriente del proceso administrativo llaman precisamente dirección.

Lo que resulta realmente inverosímil es que Terry explicita que llamó actuating a dicha función porque el empleo de esta palabra "[...] es apropiado para la función administrativa que se refiere al suministro de fuerza estimulante al grupo" (1971: 163), lo cual debería haber bastado al traductor para percatarse de que ejecución era una pésima opción para traducir este concepto y que en cambio motivación era una magnífica alternativa. Igualmente, nos asombran otras aberraciones provocadas por esta defectuosa traducción: según ésta, el escritor estadunidense dice "Se puede presentar un resumen de estas funciones fundamentales de la administración como 1) planeación, para [...], 2) organización, para [...], 3) la ejecución de los miembros del grupo (sic) para que lleven a cabo sus tareas con entusiasmo [...]" (1971:163-164, negritas nuestras), a lo que uno se pregunta ¿la "ejecución de los miembros" en un paredón o en la silla eléctrica? Queda aquí claro que si en lugar de lo que escribió el traductor hubiera redactado "la motivación de los miembros del grupo para que lleven a cabo sus tareas con entusiasmo" cobraría sentido lo que actualmente es un disparate. Asimismo, según el traductor, Terry dice lo que transcribimos a continuación, en lo cual hemos insertado varios paréntesis con la palabra correcta "motivación" en seguida de la incorrecta "ejecución"; si en lugar de ésta leemos motivación, aquí también advertiremos que adquiere coherencia y claridad lo que de otra manera resulta un sinsentido:

Básicamente, la ejecución (motivación) principia dentro de uno mismo y no dirigiendo a otros. Un gerente que no está motivado para el éxito y el progreso, hace imposibles la ejecución (motivación) de otros. Sin embargo, es difícil llegar a tener ejecución (motivación) propia ${ }^{12}$. Nace de un fuerte deseo, de una sensación intensa y de una disposición entusiasta para lograr un objetivo sin que importen los obstáculos que deban vencerse (1971: 488).

\footnotetext{
${ }^{12}$ Para mayor claridad, aquí se podría haber escrito también "[...] es difícil llegar a tener automotivación”, en lugar de "[...] es difícil llegar a tener motivación propia".
} 
La falla que hemos venido analizando tiene una gran trascendencia considerando que: 1) tergiversa mucho en sus propios fundamentos el pensamiento del influyente autor, particularmente en toda la parte IV del libro citado (titulada erróneamente “ejecución”), que abarca nada menos que cinco capítulos (130 páginas), de los cuales destaca el primero (capítulo 17 del libro) por repetir una y otra vez el error mencionado, dando lugar a frases absurdas como las mencionadas. Esta distorsión ha hecho creer a los lectores de habla hispana que, según Terry, la administración incluye la realización por parte del administrador del trabajo que planeó, organizó, etc., lo cual es incorrecto puesto que para el autor, y para la generalidad de los adeptos a la corriente del proceso administrativo, la administración es lograr objetivos a través de lo que realizan otros (los subordinados); 2) la citada obra ha tenido una enorme difusión entre los profesionales universitarios de administración de muchas generaciones, por lo menos desde 1961 (año de la traducción más antigua que hemos podido encontrar), incluyendo las de una gran proporción de los profesores de hoy en día. Es por ello que el modelo de proceso administrativo que divide éste en planeación, organización, ejecución, y control es uno de los más reconocidos, sin que se tenga conciencia de que se trata de una tergiversación del modelo de Terry. Adicionalmente, en las ediciones del texto aparecidas a partir de 1985 tras el deceso del autor — corregidas y actualizadas por Stephen Franklin, coautor desde ese entonces- persiste el importante desacierto, dado que se conserva el traductor de las ediciones previas. Por otra parte, es digno de llamar la atención el hecho de que ninguno de los dos revisores sucesivos de la traducción (el de la edición de 1971 y el de las demás ediciones a partir de 1985) reparó en los crasos errores apuntados, lo cual refuerza nuestra creencia de que, salvo honrosas excepciones, los revisores técnicos no cumplen satisfactoriamente su encomienda.

\section{Las distorsiones en la versión española de una obra pionera, The Functions of the Executive, de Chester Barnard}

Chester Barnard publicó en 1938 The Functions of the Executive, "Uno de los libros más influyentes que se ha publicado en todo el campo de la administración", según Koontz y Weihrich (1994: 43), y que mereció el siguiente comentario del Premio Nobel H. Simon, en la cuarta edición (1997) de su afamado Administrative Behavior: "Con el finado Chester I. Barnard tengo una deuda especial: en primer lugar, por su libro Las funciones del ejecutivo, el cual ejerció una influencia mayor en mi pensamiento sobre la administración [...]" (1997: xiii). Lamentablemente, esta obra de tanta trascendencia ha sufrido abundantes tergiversaciones y de muy diversa índole al ser traducida a la lengua castellana, algunas de ellas sumamente 
graves. Hemos descubierto tales distorsiones a pesar de que hasta la fecha únicamente hemos podido examinar un capítulo de la versión española del texto referido, el XV, que lleva el mismo título que la obra completa: Las funciones de los elementos dirigentes. Con base en esta muestra, es lógico presumir que el resto del libro está igualmente plagado de yerros; verificaremos nuestra conjetura en un futuro cercano, al proseguir con nuestra investigación. Expondremos en seguida algunos ejemplos de las faltas que hemos detectado hasta el día de hoy.

Para empezar, aunque no se trata de una de las incorrecciones graves, debemos advertir que la traducción que se hizo del título del libro y del capítulo mencionado no es del todo afortunada: The Functions of the Executive pudo muy bien haber sido traducido como Las funciones del ejecutivo o bien Las funciones del dirigente. La traducción Las funciones de los elementos dirigentes agrega una palabra innecesaria, elementos, que lo único que hace es complicar la redacción, haciéndola confusa en muchos pasajes de los muchos más en los que se tiene que hacer referencia a dicha clase de personal tanto en este capítulo como en el resto del texto.

Pasando a errores de mayor envergadura, apenas en el segundo párrafo del capítulo se escriben las siguientes líneas, en las cuales hemos resaltado con negritas lo que se tradujo equivocadamente y hemos colocado un guión bajo en donde el traductor omitió, por error, la palabra "no", convirtiendo así una negación en una afirmación ${ }^{13}$ :

Es de importancia observar, en cambio, que _ toda la labor realizada por las personas que ocupan puestos dirigentes está relacionada con funciones de dirección, con la coordinación de las actividades de los demás. Parte de la labor de tales personas, aunque de organización, no es labor dirigente (Barnard, 1959: 15).

Para ser fiel a lo que realmente dijo Barnard, la traducción debería haber dicho lo siguiente:

Es importante observar, sin embargo, que no todo el trabajo realizado por personas que ocupan puestos ejecutivos está relacionado con las funciones ejecutivas, es decir, con la coordinación de las actividades de otros. Parte de la labor de tales personas, aunque es trabajo de organización, no es trabajo ejecutivo ${ }^{14}$.

\footnotetext{
${ }^{13} \mathrm{Al}$ citar aquí el párrafo mal traducido y escribir poco más adelante su traducción correcta, lo hemos hecho como si se tratara en ambos párrafos de una cita de más de cinco renglones (es decir, con letra más pequeña y con un margen del lado izquierdo). Ello porque así se facilita la lectura comparativa de ambos párrafos. Hemos aplicado el mismo criterio en varios casos iguales subsecuentes.

${ }^{14}$ Traducción nuestra de: "It is important to observe, however, that not all work done by persons who occupy
} 
Además de distorsionar totalmente lo dicho por el autor, la incorrecta traducción tiene dos consecuencias más que podrían hacer pensar al lector que Barnard está hablando ilógicamente: 1) la afirmación hecha en sus primeros tres renglones, hasta donde aparece el punto y seguido, es contradictoria con la negación que se hace inmediatamente después: en dichos renglones se asevera, en resumen, que toda la labor hecha por quienes desempeñan puestos dirigentes está relacionada con funciones directivas, mientras que en seguida se dice que parte de dicha labor no es directiva; 2) la misma afirmación de los tres primeros renglones es una perogrullada, ya que, en otras palabras, dice que toda la labor de los dirigentes está relacionada con funciones de dirigentes.

Unas páginas adelante, según el traductor, nuestro autor dice lo siguiente, que, como se podrá ver, resulta incomprensible ${ }^{15}$ :

En otros términos, los puestos de comunicación y el "asignar" los servicios de una persona son fases complementarias de la misma cosa. El centro de comunicación es el rendimiento organizativo de una persona en un lugar. Las personas sin puesto no pueden operar como dirigentes. No proponen nada sino potencialmente. A la inversa, los puestos vacantes están tan difuntos como centros nerviosos muertos. Ello es porque los elementos dirigentes, cuando funcionan estrictamente como dirigentes, son incapaces de apreciar a los hombres en abstracto, en un vacío de organización, por decirlo así. Los hombres no son ni buenos ni malos, sino buenos o malos sólo en esta o aquella posición. Y ello porque frecuentemente "cambian la organización", la disposición de los puestos, si no hay hombres disponibles a propósito para ocuparlos (1959: 17).

Según nuestra traducción libre, lo que Barnard realmente dice es lo que sigue ${ }^{16}$ :

En otros términos, la creación de un puesto como medio de comunicación y la asignación al mismo de los servicios de una persona son aspectos complementarios de la

executive positions is in connection with the executive functions, the coordination of activities of others. Some of the work of such persons, though organization work, is not executive." (1960: 215)

${ }^{15}$ Aquí y en lo sucesivo seguiremos la misma práctica que aplicamos tanto en la última cita de Barnard (mal traducida) como en la propuesta que hicimos para su traducción correcta: resaltaremos con negritas lo importante de lo que se tradujo equivocadamente y al escribir la traducción correcta también subrayaremos con negritas las correcciones verdaderamente importantes que hayamos hecho. De la misma manera, al transcribir los pasajes correspondientes en su versión original, en inglés, también haremos notar con negritas las palabras o frases importantes que fueron mal traducidas.

${ }^{16}$ La principal libertad que nos hemos tomado en esta traducción es la de traducir (en el primer renglón) "communication position", que literalmente significa "puesto de comunicación", como "la creación de un puesto como medio de comunicación"; hemos considerado indispensable agregar palabras que no aparecen en esta oración en el texto original en vista de que sólo así se puede ser fiel en español a la idea expresada por el autor, la cual 
misma cosa. El centro de comunicación es el servicio a la organización prestado por una persona en un determinado lugar. Las personas sin puesto no pueden operar como ejecutivos pues no significan otra cosa más que potencialidad. Por el contrario, los puestos que se encuentran vacantes están tan difuntos como los centros nerviosos muertos. Esta es la razón por la cual los ejecutivos, cuando funcionan estrictamente como tales, son incapaces de evaluar a los hombres en abstracto, en un vacío de organización, por decirlo así. Los hombres no son ni buenos ni malos, sino buenos o malos sólo en este o aquel puesto. Este es el motivo por el cual los ejecutivos frecuentemente "cambian la organización”, la disposición de los puestos, si no hay hombres disponibles adecuados para ocuparlos. ${ }^{17}$

Poco más adelante, después de cometer muchos otros errores, el traductor obscurece así el pensamiento de Barnard:

Y tanto se comprende generalmente, cuanto que, aunque el dinero u otros alicientes materiales se hayan de utilizar normalmente para pagar a las personas responsables, la responsabilidad en sí misma no proviene de tales alicientes (1959:19).

Acudiendo a la fuente original, podemos disipar los nubarrones impuestos por el traductor para descubrir lo que realmente escribió el autor:

Es más bien generalmente entendido que aunque el dinero u otros estímulos materiales deben usualmente ser pagados a las personas responsables, la responsabilidad en sí misma no proviene de tales incentivos ${ }^{18}$.

se entiende en el mismo sentido que le hemos dado si se lee el párrafo inmediato anterior, particularmente los últimos renglones, que dicen: "Como la comunicación sólo se realizará a través de la gestión de personas, la selección de éstas para las funciones dirigentes es el método concreto de establecer los medios de comunicación, aunque haya de ser seguido inmediatamente por la creación de puestos, esto es, de un sistema de comunicación; y especialmente en las organizaciones establecidas habrá de haber puestos para ser cubiertos en caso de vacantes." Nótese que inmediatamente después se inicia el renglón a que nos referimos diciendo precisamente "En otros términos...". Cabe puntualizar que toda buena traducción tiene como propósito traducir lo más fielmente posible el pensamiento original del autor, es decir, sus ideas, sus razonamientos, no sus palabras literales una a una, y que para ello a menudo tiene que añadir palabras no expresadas en el original o eliminar otras que sí aparecen en él. Dada la propia naturaleza de la lengua española y la de la inglesa, con frecuencia es necesario agregar palabras en el español al traducir del inglés.

${ }^{17}$ Traducción nuestra de: "In other words, communication position and the "locating" of the services of a person are complementary phases of the same thing. The center of communication is the organization service of a person at a place. Persons without positions cannot function as executives, they mean nothing but potentiality. Conversely, positions vacant are as defunct as dead nerve centers. This is why executives, when functioning strictly as executives, are unable to appraise men in the abstract, in an organization vacuum, as it were. Men are neither good nor bad, but only good or bad in this or that position. This is why they not infrequently "change the organization", the arrangement of positions, if men suitable to fill them are not available." (1960: 218).

${ }^{18}$ Traducción nuestra de: "It is rather generally understood that although money or other material inducements must usually be paid to responsible persons, responsibility itself does not arise from such inducements." (1960: 220-221). 
Como se habrá podido advertir, hasta ahora hemos señalado distorsiones producidas por fallas en la traducción de frases u oraciones compuestas por palabras que pertenecen primordialmente al lenguaje ordinario. Existen muchos más casos de esta índole en el texto que hemos examinado, al grado de que es difícil encontrar una página en la que no emerjan los desaciertos; no obstante, dadas las limitaciones propias de la naturaleza del presente artículo y con el objeto de no cansar al lector, no abundaremos más en ejemplos de esta clase. En cambio, procederemos a ofrecer algunas cuantas muestras de deformación de las ideas de Barnard provocadas por la traducción desacertada de términos especializados de la administración.

Uno de los errores más graves en la traducción de terminología especializada en que incurre el traductor es al traducir informal organization — cuya correcta, ampliamente difundida y aceptada traducción es organización informal - como organización irregular. Las repercusiones negativas de tan inverosímil error son de gran escala: trastocan un concepto que es fundamental de The Functions of the Executive y que, por la misma razón, es empleado en incontables ocasiones en el texto. La extraña traducción del término le pareció tan importante al editor de la versión del libro que hemos venido empleando, que mereció su siguiente nota aclaratoria a pie de página, la cual denota que él cree que es Barnard y no su traductor quien está empleando el término organización irregular: "El autor utiliza el término 'organizaciones irregulares' para referirse a lo que actualmente suele denominarse 'organización informal' ” (1959: 21). Veamos a continuación algunos ejemplos del empleo por el traductor del término erróneo mencionado con el fin de apreciar como empaña la claridad de los pasajes:

Se ha hecho hincapié varias veces en que la organización irregular es necesaria para la organización formal, particularmente en lo que se refiere a la comunicación (1959: 21).

Aunque nunca oí afirmar que ésta fuera una función dirigente o que exista una cosa tal como una organización dirigente irregular, en todas las buenas organizaciones he observado que se le presta la más cuidadosa atención. En todas ellas funcionan las organizaciones irregulares (1959: 22).

Para resumir: la primera función dirigente es la de desarrollar y mantener un sistema de comunicación. Esto implica conjuntamente un esquema de organización y un personal dirigente. El procedimiento mediante el cual se logra este último incluye fundamentalmente la selección de los hombres y el ofrecimiento de incentivos, las técnicas de control que permitan eficacia en el nombramiento, degradación y cese de los hombres y, finalmente, el asegurar una organización irregular cuya propiedad esencial sea la compatibilidad del personal. Las funciones principales de esa organización irregular son expandir los medios de comunicación, aminorar la necesidad de decisiones formales, reducir al mínimo 
las influencias indeseables y fomentar las deseables que concuerdan con el esquema de las responsabilidades formales (1959: 24).

Otra equivocación terminológica del traductor es la de confundir entre sí los vocablos ingleses personnel y personal. El primero, es un sustantivo que significa personal, en el sentido de personas que laboran en alguna organización, como, por ejemplo, en la expresión personnel department (departamento de personal). En cambio, la palabra inglesa personal es un adjetivo, lo mismo que en español, que además se escribe exactamente igual que en nuestro idioma y que significa exactamente lo mismo: perteneciente o relativo a la persona. Es en este sentido que se emplea al decir, por ejemplo, "esto es un asunto personal que no deseo discutir". La importancia de esta confusión, que vista en forma asilada aparentemente es nula, es evidente cuando vemos lo ininteligible que resultan las siguientes líneas, en las cuales se tradujo erradamente personnel como personal:

Los problemas personales son un caso especial de los problemas personales generales: el reclutamiento de miembros que tengan las cualidades apropiadas y el desarrollo de los incentivos, de los alicientes, de la persuasión y de la autoridad objetiva que pueda convertir esas cualidades en servicios efectivos dirigentes en la organización (1959: 18).

Las pasadas líneas cobran claridad cuando se traducen de manera correcta; si no resultan cabalmente comprensibles en nuestra traducción es por encontrarse descontextualizadas:

Los problemas de personal son un caso especial de los problemas de personal generales: el reclutamiento de miembros que posean las cualidades apropiadas, por un lado, y el desarrollo de los estímulos, incentivos, persuasión y autoridad objetiva que puedan convertir esas cualidades en servicios ejecutivos efectivos para la organización, por el otro. ${ }^{19}$

La traducción equivocada de personnel se repite una y otra vez en el libro, dando lugar a múltiples pasajes más que son incomprensibles.

El último ejemplo de término especializado mal traducido que señalaremos es el que se comete al traducir line executives, que significa ejecutivos de línea (por

\footnotetext{
${ }^{19}$ Traducción nuestra de: "The personnel problems are a special case of general personnel problems -the recruiting of contributors who have appropriate qualifications, and the development of the inducements, incentives, persuasion and objective authority that can make those qualifications effective executive services in the organization." (1960: 219).
} 
oposición a ejecutivos staff), como líneas de dirigentes, que, además de no ser un término reconocido, resulta incomprensible, como se advierte a continuación: "Ello se hace posible por la elaborada y a veces delicada disposición para corregir los errores provenientes de las faltas de superespecialización y la exigüidad de las líneas de dirigentes" (1959: 20).

Para finalizar con el análisis de la versión española de The Functions of The Executive, señalaremos que no deja de llamarnos la atención el hecho de que el traductor equivoque incluso al traducir vocablos y frases que son básicos tanto en inglés como en nuestro idioma, tales como however (sin embargo, no obstante), traducido por "en cambio" (pp. 15, 19 y otras); supervision (supervisión), traducido como "intervención" (p. 21); training (capacitación, entrenamiento) por "ejercicio" (p. 20); y this is why (ésta es la razón por la cual o esto es por lo que), traducido indistintamente como "y ello porque" (p. 17), o "ello es porque" (p. 17).

\section{Los desatinos en la traducción de Organización y burocracia de Mouzelis}

Más consultada y comentada por los cultivadores de la teoría de la organización y de los estudios organizacionales que por los académicos de la administración — seguramente debido a su orientación eminentemente teórica—, la obra de Nicos Mouzelis Organización y burocracia. Un análisis de las teorías modernas sobre organizaciones sociales (1973), se ha ganado un lugar sobresaliente en la literatura especializada en organizaciones, de ahí que haya sido traducida de su lengua original, inglés, por lo menos al español. Desafortunadamente, esta obra también se suma a muchas otras que presentan deficiencias en su traslación.

Uno de los errores más importantes que comete quien se encargó de redactar la versión española de esta obra radica en traducir managerial tradition como "tradición de la ordenación científica”. Mouzelis divide su libro en tres grandes partes; la primera y la segunda las dedica al examen de las que considera como las dos grandes tradiciones de análisis de las organizaciones: el estudio de la burocracia, que empieza con autores tales como Marx, Weber y Michels, y "the manageral tradition", que engloba principalmente a Taylor y el movimiento de la administración científica, Fayol y la escuela clásica de administración, la escuela de las relaciones humanas y $\mathrm{H}$. Simon y el enfoque de la toma de decisiones. De lo anterior se desprende que la traducción correcta de the managerial tradition es "la tradición de la administración", aunque también sería admisible "la tradición de la teoría administrativa" o, como última alternativa, "la tradición de la gestión", 
pero nunca "la tradición de la ordenación científica". Dado que el error se comete al designar una de las tres grandes partes del libro y consecuentemente a lo largo de la misma, se convierte en una distorsión conceptual grave. Para aquilatarla basta pensar, por ejemplo, que tanto el pensamiento de Herbert Simon como el de Elton Mayo y seguidores, todos ellos fuertes críticos del taylorismo, quedan absurdamente ubicados como parte de la escuela de la administración científica, de la cual Taylor es el representante por antonomasia.

En el nivel terminológico, probablemente la equivocación más notoria de la versión española de la obra que nos ocupa es la de traducir los vocablos management (administración) y managerial (administrativo o de la administración), además de erróneamente, de manera inconsistente, con lo cual se incrementa la confusión. La mayoría de las veces se traducen como "ordenación” y "de la ordenación" respectivamente, como en el caso abordado en al párrafo anterior y cuando scientific management es traducido como "ordenación científica" en lugar de administración científica, lo cual sucede decenas de veces a lo largo de la obra; por ejemplo, el yerro aparece en las páginas 8, 89, 92, 95, 96, 98, 99, 104, 105, 106, 131 y 183. En otras ocasiones management y managerial son traducidos como "dirección" y "directorial" (sic), respectivamente (por ejemplo, el primer término en las páginas 97, 98 y 101; el segundo en las números 99 y 101). En el párrafo siguiente podemos apreciar mejor, gracias a su ubicación contextual, lo inadecuadas que resultan la incorrecta traducción de management y su inconsistencia, así como otras fallas menores de traslación:

La literatura de la ordenación científica no sólo se ocupa de la manera de construir un marco conceptual formal. [...] Por ello, la otra preocupación principal de la escuela universalista ha sido el examen del proceso de dirección. Este viene generalmente definido como "un proceso de obtención de cosas hechas por la gente que trabaja en grupos organizados". [...] Además, del análisis de este proceso, la construcción del correspondiente marco conceptual y la formulación en este campo de un cierto número de principios, se espera que pueda construirse una teoría de la ordenación [...] Más concretamente, el análisis del proceso de ordenación científica continúa en términos de las actividades o funciones básicas del director (planificación, coordinación, control, etcétera) [...] (1973: 98).

Lo que realmente quiso decir Mouzelis es, según nuestra traducción:

La literatura de la administración no sólo se ocupa de la manera de construir un marco conceptual formal. [...] Por ello la otra preocupación principal de la escuela universalista es el examen del proceso de administración o proceso administrativo, el cual generalmente es definido como "el proceso de obtener que las cosas sean hechas por la gente 
que trabaja en grupos organizados”. [...] Además, mediante el análisis de este proceso, la construcción de su correspondiente marco conceptual y la formulación en este campo de una serie de principios, se puede construir una teoría de la administración [...] Dicho con más precisión, el análisis del proceso administrativo continúa en términos de las actividades o funciones básicas del administrador (planeación, coordinación, control, etc.) $[\ldots] .{ }^{20}$

Nótese además que, como consecuencia de haber traducido erradamente el título de la segunda parte del libro como "La "tradición de la ordenación científica", en lugar de "la tradición de la administración" o "la tradición de la teoría administrativa", en la primera línea del párrafo citado (el cual pertenece a esa segunda parte) el traductor se ve obligado a escribir "La literatura de la ordenación científica", siendo que lo que Mouzelis quizo decir es "La literatura de la administración" en general, sin referirse a ninguna escuela en particular. Igualmente, en las últimas líneas del mismo párrafo el traductor se ve precisado a decir "proceso de ordenación científica", distorsionando considerablemente la idea original pues en realidad el autor dijo "proceso administrativo" o "proceso de administración".

Cierto es que management ha sido traducido al español en muchas obras con diversos vocablos, que suelen variar según la nacionalidad de la edición, pero frecuentemente cambiando también al interior de un mismo país. Así, por ejemplo, se ha traducido y difundido ampliamente como administración, gestión y dirección en México, aunque predominando el primer término; gestión y dirección en España; gerencia y administración en Argentina; gerencia en Venezuela; dirección en Chile y Cuba, etc. Pero es igualmente cierto que el uso de todos los susodichos términos, aunque no sea del todo conveniente, tiene razones lógicas y que, hasta donde sabemos, tras muchos años de prestar atención a este asunto, no existen otros traductores que empleen la peculiar, poco lógica y reduccionista traducción de "ordenación".

\footnotetext{
${ }^{20}$ Traducción nuestra de: "The literature of management is not only concerned with how to build a formal framework [...] So the other main preoccupation of the universalist school is the examination of the process of management. This is usually defined as 'a process of getting things done by people who operate in organized groups'. [...] Moreover, by analyzing this process, by building a conceptual framework for it and by formulating on this ground a number of principles, a theory of management can be built up [...] More precisely, the analysis of the process of management goes on in terms of the basic activities or functions of the manager (planning, co-ordinating, controlling, etc.) (1973 b: 89-90).
} 
Todo el libro Organización y burocracia se encuentra plagado de otras equivocaciones tanto graves como menores, pero aún éstas contribuyen a dificultar la lectura más allá de la que por su propia naturaleza pueda presentar la versión original. Las graves por supuesto traicionan el pensamiento de Mouzelis y con ello se convierten en un escollo a la difusión y avance del conocimiento.

\section{Hacia traducciones más rigurosas de las obras sobre organizaciones: ¿qué se puede hacer?}

No obstante que las evidencias que hemos ofrecido de que existen serias deficiencias en la traducción de obras importantes de administración han sido extraídas de sólo una pequeña muestra de libros, aunadas a las que hemos observado en muchos otros textos, nos permiten aseverar que los estudiosos de dicha disciplina hispano parlantes tenemos ante nosotros un problema que no conviene de ninguna manera soslayar o subestimar. El escollo que significa para la difusión y el avance del conocimiento no es menor y se les presenta no sólo a quienes no tienen un dominio suficiente de la lengua inglesa, idioma predominante para estos fines, sino también a quienes aún poseyéndolo no tienen fácil acceso a las versiones originales en inglés de infinidad de libros, y consecuentemente tienen también que conformarse con leer sus traducciones. Cierto es que el problema, gracias a las enormes facilidades para acceder a revistas especializadas vía Internet, resulta menos grave para quienes conociendo suficientemente bien inglés y/o francés pueden recurrir a este medio, pero también es verdad que al menos en México estos académicos son los menos y que los libros, que por lo general no están disponibles electrónicamente por la Web, siguen conteniendo cuestiones importantes que no aparecen en dichas revistas.

Por otra parte, el problema no es fácilmente visible a primera vista, suele presentarse subrepticiamente, lo cual lo hace aún más dañino. Son tan abundantes las deficientes traducciones de obras de administración, que es probable que ya nos haya sucedido que pasajes de obras traducidas del inglés que nos han parecido obscuros y hasta faltos de inteligencia no se deban al autor sino a una incorrecta traducción, y que ella nos haya hecho malinterpretar los razonamientos originales. En otros casos en que los yerros no son tan distorsionadores, por lo menos nos pueden haber dificultado la lectura más allá de la propia complejidad de las ideas originales del pensador. 
Lo primero que tenemos que hacer para tratar de atenuar esta problemática es, obviamente, identificar sus causas más importantes. La más evidente es la falta de preparación adecuada de los traductores. La labor de éstos es más compleja y delicada de lo que podría parecer a quienes jamás han pensado sobre el particular y a los que nunca han realizado traducción con fines académicos. Exige por lo menos cuatro cualidades sine qua non: un buen dominio de comprensión del idioma desde el cual se traduce; un buen dominio de la lengua escrita a la que se traduce; un buen conocimiento de la disciplina y particularmente del área a la que pertenece el texto por traducirse; y poseer un gran sentido de responsabilidad académica, que usualmente se finca en una vocación por la verdad. Esta última cualidad debe ser lo suficientemente firme como para impedir que el traductor desfallezca cuando tenga que emprender laboriosas indagaciones en muy diversas fuentes, ya sean respecto a las dos lenguas en cuestión o al área de conocimiento del asunto traducido, con el fin de lograr una correcta traducción de una frase o hasta de un solo término que ofrezca una dificultad especial y cuya desatinada traducción pueda tergiversar una idea importante. La exigencia de tales cualidades explica por qué la traducción de los libros más sobresalientes en otros campos disciplinarios, ciencias, humanidades y artes, incluyendo las más grandes obras de la humanidad, es usualmente encomendada por las editoriales serias a grandes maestros en el ámbito correspondiente. Así, por ejemplo, $L a$ lógica de la investigación científica de Popper fue traducida por el propio autor, de su lengua original, inglés, al alemán; Demóstenes: la agonía de Grecia, del destacado filósofo Jaeger, fue trasladada del inglés al español por el también distinguido filósofo Eduardo Nicol; ${ }^{21}$ varias obras clásicas griegas, incluyendo La Ilíada, fueron vertidas a nuestra lengua nada menos que por Alfonso Reyes; Julio Cortázar tradujo al castellano los cuentos de Edgar Allan Poe; y Jorge Luis Borges hizo lo propio con Orlando de Virginia Woolf. Igualmente, cuando la variedad de las disciplinas implicadas en una sola obra y/o la magnitud de la misma lo amerita, son encargadas a un grupo de reconocidos especialistas ad hoc. Tal es el caso, verbigracia, de Economía y sociedad, de Max Weber, trasladada al español por cinco grandes intelectuales, entre los que figuran José Ferrater Mora, Eduardo García Máynez y José Medina Echavarría.

\footnotetext{
${ }^{21}$ La importancia concedida por los autores al trabajo de traducción destaca por dos hechos: primero, que en ocasiones ellos mismos emprenden el laborioso esfuerzo de realizarla, en segundo lugar, es frecuente que expresen en la propia obra traducida un reconocimiento especial, personalizado, al traductor correspondiente. Por ejemplo, W. Jaeger dedica varias líneas de su prefacio a agradecer muy cumplidamente a Eduardo Nicol por el "excelente trabajo" realizado en la traducción de su Demóstenes.
} 
El dominio de la disciplina, y particularmente del área de conocimiento en cuestión que debe poseer el traductor, es crucial en virtud de que para trasladar un pensamiento a una lengua distinta de aquella en la que fue originalmente concebido es absolutamente indispensable, antes que nada, comprender a cabalidad dicho pensamiento, lo cual es generalmente imposible si no se tienen conocimientos especializados en la materia. Por esto consideramos riesgoso que se traduzcan textos de campos del conocimiento que no sean del dominio del traductor, como sucede generalmente con las traducciones de obras administrativas realizadas por traductores profesionales, a menos que se tenga la plena seguridad de que los revisores técnicos, que de unos años a la fecha emplean algunas editoriales para corregir los errores cometidos por aquéllos, realicen su trabajo con profesionalismo y diligencia. Lamentablemente, a menudo los revisores técnicos no cumplen concienzudamente con su encomienda; de hacerlo, el revisor de la traducción de los Principios de administración de Terry, por ejemplo, no hubiera pasado por alto el craso, evidente y reiterado error de traducir actuating como ejecución, como comentamos en la sección dedicada a tal yerro. También hubieran sido corregidas por el respectivo revisor técnico las equivocaciones que señalamos en la sexta edición de la obra analizada de Koontz y O'Donnell. Nos parecería, por tanto, conveniente que las editoriales de obras de administración consideraran la opción de que las traducciones las realizaran los mejores revisores técnicos, ya probados, en sustitución de los traductores profesionales, lo cual podría permitirles pagar honorarios más elevados a los primeros por tan laboriosa e importante tarea, gracias al ahorro obtenido al prescindir de los segundos. Los traductores profesionales bien podrían ocuparse exclusivamente de las materias no especializadas.

No obstante la trascendencia que tiene la traducción de obras, en la esfera editorial de libros de administración muy a menudo no se aquilata de la debida manera, dando lugar a que se otorgue poco cuidado a la selección de traductores y revisores técnicos apropiados. De hecho, nos parece que este descuido es la principal causa de la problemática que nos ocupa. Muestra de su existencia es el hecho de que con frecuencia las traducciones son encomendadas a personas que no poseen cabalmente las cualidades a que nos referimos anteriormente. Algunas de ellas denotan tener un nivel aceptable de conocimientos de las dos lenguas implicadas, como frecuentemente es el caso de los traductores profesionales, pero no tienen los conocimientos propios del campo en el que se inscribe la obra, la mayoría de las veces por no tener los estudios correspondientes. En el caso de las diversas versiones españolas que analizamos previamente de Principles of Management de Koontz y O' Donnell, por ejemplo, tres de los once traductores aparecen acreditados como "traductor profesional", uno como contador público y los siete restantes sin 
especificar su profesión; sin embargo, se podría suponer que dos de estos últimos tienen estudios de una carrera afín, a juzgar por las instituciones de su filiación académica (ver cuadro 2). De manera que, en conclusión, aún presumiendo que dos de los siete traductores cuya profesión no se especifica tuvieran estudios adecuados, son nueve, la mayoría, los que no los tienen. En otros casos, el traductor o el revisor técnico sí cuentan con la formación y conocimientos pertinentes a la materia objeto de la traducción, pero su dominio del inglés y/o del español dista mucho de ser suficiente. Este caso, nos parece, se da mucho más frecuentemente en lo relativo a los revisores técnicos; ¿creerán acaso, muchos de ellos, que se puede revisar a conciencia una traducción sin dominar la lengua original? ¿estimarán que no es necesario comprender enteramente el texto en inglés para supervisar su traducción? Al parecer, muchos sí lo piensan.

Mientras las casas editoriales no se ocupen de la problemática que hemos expuesto, de la cual probablemente no están conscientes, y los traductores y revisores técnicos ineficientes no asuman plenamente la responsabilidad que les corresponde, de la cual algunos probablemente tampoco tienen clara conciencia, seguirán apareciendo aquí y allá traducciones que alteran substancialmente lo realmente escrito por los autores. Por consiguiente, no nos queda más camino que recomendar por lo pronto a los lectores de obras de administración traducidas que procuren recurrir a las versiones originales y que si no tienen los suficientes conocimientos en la lengua correspondiente, se esfuercen por lograrlos. Es indudable que se verán justamente recompensados por ello. 


\section{Cuadro 1}

Traducciones divergentes de tres términos en diversas ediciones en español de la obra publicada originalmente por Koontz y O'Donnell con el título

Principles of Management: An Analysis of Managerial Functions, y editada sucesivamente con variaciones de coautor y de título

\begin{tabular}{|c|c|c|c|}
\hline \multirow[b]{2}{*}{$\begin{array}{l}\text { Edición } \\
\text { en } \\
\text { español }\end{array}$} & \multicolumn{2}{|c|}{$\begin{array}{lll}\text { T R D U C C I O NES } & \text { DE } & \text { LOS }\end{array}$} & \multirow{2}{*}{$\begin{array}{c}\text { T É R M I N O S } \\
\text { STAFFING } \\
\text { (traducción correcta: } \\
\text { integración de personal) }\end{array}$} \\
\hline & $\begin{array}{c}\text { SPAN OF CONTROL } \\
\text { (traducción correcta: } \\
\text { tramo de control) } \\
\end{array}$ & $\begin{array}{l}\text { SPAN OF MANAGEMENT } \\
\text { (traducción correcta: } \\
\text { tramo de administración) }\end{array}$ & \\
\hline $\begin{array}{c}2^{\mathrm{a}} \\
(1961)\end{array}$ & $\begin{array}{l}\text { 1) alcance del control } \\
\text { (p. 65) }\end{array}$ & $\begin{array}{l}\text { 1) alcance de la dirección } \\
\text { (p. 65) }\end{array}$ & $\begin{array}{l}\text { 1) formación de los cuadros } \\
\text { (pp. } 315 \text { y ss.) }\end{array}$ \\
\hline $\begin{array}{c}3^{\mathrm{a}} \\
(1970)\end{array}$ & $\begin{array}{l}\text { 1) área de control } \\
\text { (p. 244) }\end{array}$ & $\begin{array}{l}\text { 1) área de la administración } \\
\text { (p. } 244 \text { y 245) }\end{array}$ & $\begin{array}{l}\text { 1) desarrollo del personal } \\
\text { (pp. } 8,12,56,431 \text { y ss.) }\end{array}$ \\
\hline $\begin{array}{c}4^{\mathrm{a}} \\
(1972)\end{array}$ & 1) área de control & 1) área de administración & 1) desarrollo del personal \\
\hline $\begin{array}{c}5^{\mathrm{a}} \\
(1977)\end{array}$ & $\begin{array}{l}\text { 1) área de control } \\
\text { (p. 260) }\end{array}$ & $\begin{array}{l}\text { 1) amplitud de comando de la } \\
\text { administración (p. 260). } \\
\text { 2) área de la administración } \\
\text { (pp. 260 y 271) } \\
\text { 3) amplitud de comando (p. 260) } \\
\text { 4) magnitud de supervisión (p. 262) } \\
\text { 5) área de supervisión (p. 262) } \\
\text { 6) amplitud de supervisión } \\
\text { (pp. 262, 263 y 276) } \\
\text { 7) amplitud de la administración } \\
\text { (pp. } 270 \text { y 271) } \\
\text { 8) amplitud de supervisión de la } \\
\text { administración (p. 276). }\end{array}$ & $\begin{array}{l}\text { 1) personal (p. VII) } \\
\text { 2) staffing (pp. 48, } 51 \text { y 55) } \\
\text { 3) "dotación de personal } \\
\text { (staffing)" (pp. 437-441 } \\
\text { y 456-457) } \\
\text { 4) "llenar posiciones (staffing)" } \\
\text { (p. 437) } \\
\text { 5) "nombramiento de personal } \\
\text { (staffing)" (p.1) }\end{array}$ \\
\hline $\begin{array}{c}6^{\mathrm{a}} \\
(1979)\end{array}$ & $\begin{array}{l}\text { 1) tramo del control } \\
\text { (pp. } 308,321)\end{array}$ & $\begin{array}{l}\text { 1) área de mando } \\
\text { (pp. } 308,309,311 \text { y ss.) } \\
\text { 2) amplitud de mando (p. 309) } \\
\text { 3) tamaño de los equipos } \\
\text { administrativos } \\
\text { (p. } 311 \text {, varias veces) }\end{array}$ & $\begin{array}{l}\text { 1) integración (pp. viii, } 78,80 \text {, } \\
499 \text { y ss.) } \\
\text { 2) integración de los recursos } \\
\text { humanos (p. 80) }\end{array}$ \\
\hline $\begin{array}{c}10^{\mathrm{a}} \\
(1994)\end{array}$ & $\begin{array}{l}\text { 1) tramo de control } \\
\text { (p. 246) }\end{array}$ & $\begin{array}{l}\text { 1) tramo de administración } \\
\text { (p. } 246 \text { y ss.) }\end{array}$ & $\begin{array}{l}\text { 1) integración de personal (pp. } 4 \text {, } \\
20-23,353 \text { y ss.) }\end{array}$ \\
\hline $\begin{array}{c}11^{\mathrm{a}} \\
(1998)\end{array}$ & $\begin{array}{l}\text { 1) tramo de control } \\
\text { (p.248) }\end{array}$ & $\begin{array}{l}\text { 1) tramo de administración } \\
\text { (p. } 248,249,250 \text { y } 252) \\
\text { 2) tramo de organización (p. 263) }\end{array}$ & $\begin{array}{l}\text { 1) integración de personal } \\
\text { (pp. } 6,7,33,36,378 \text { y ss.) }\end{array}$ \\
\hline $\begin{array}{c}12^{\mathrm{a}} \\
(2003)\end{array}$ & $\begin{array}{l}\text { 1) tramo de control } \\
\text { (p. 244) }\end{array}$ & $\begin{array}{l}\text { 1) tramo de administración } \\
\text { (pp. } 244 \text { y ss.) }\end{array}$ & $\begin{array}{l}\text { 1) integración de personal (pp. 7, } \\
23,26,32,33,360 \text { y ss.). }\end{array}$ \\
\hline TOTAL & $\begin{array}{l}3 \text { términos diferentes } \\
\text { ( } 2 \text { erróneos })\end{array}$ & 14 términos diferentes (13 erróneos) & $\begin{array}{l}9 \text { términos diferentes ( } 7 \\
\text { erróneos), más el uso del } \\
\text { término staffing sin traducir }\end{array}$ \\
\hline
\end{tabular}




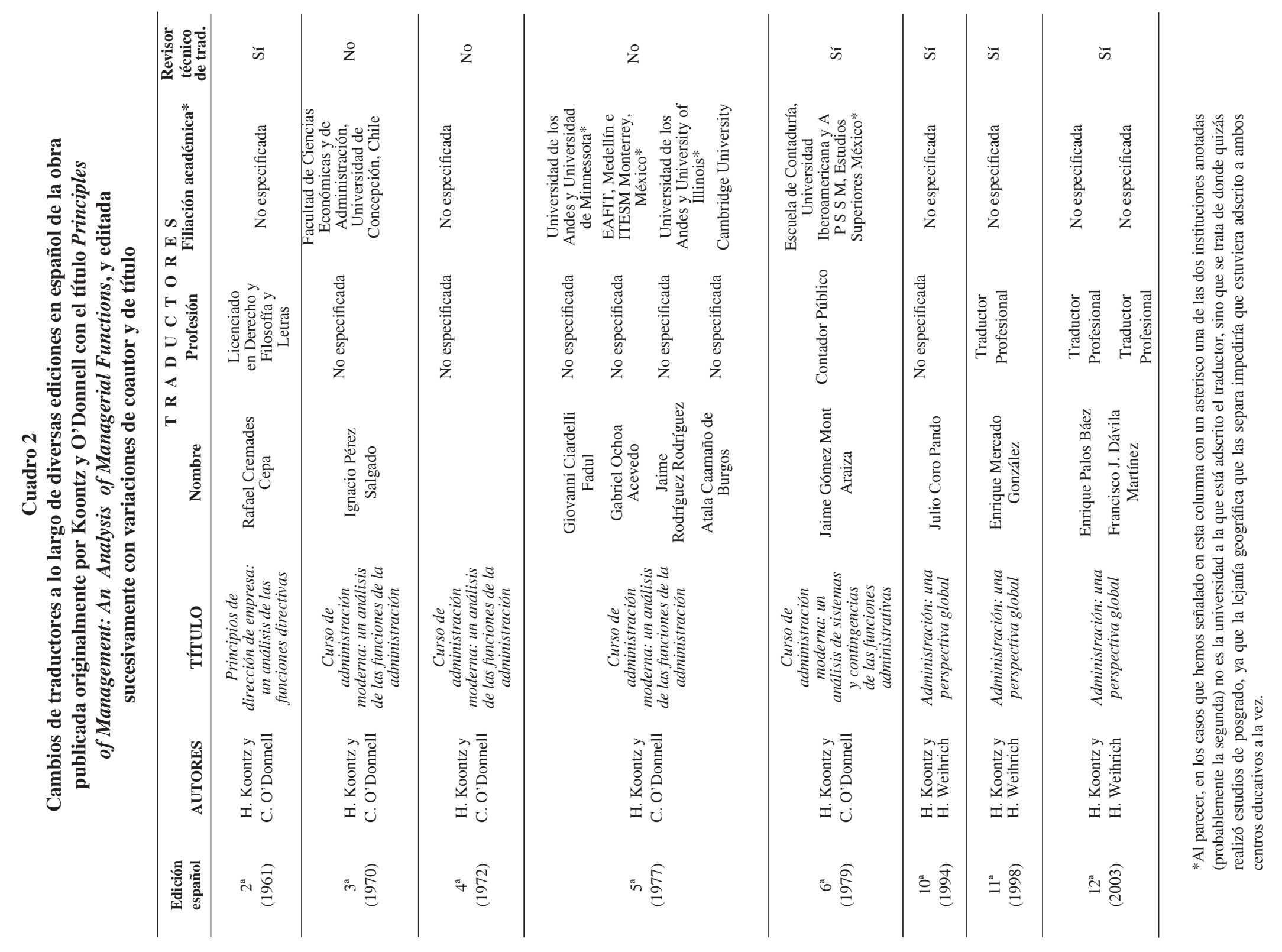




\section{Referencias}

Barnard, Chester I. (1960). The Functions of the Executive. Cambridge: Harvard University Press, 334 pp.

(1959). "Las funciones de los elementos dirigentes" (reproducción del capítulo XV de la obra del mismo título y autor, cuyo título original es The Functions of The Executive), Anzizu, José M. (compilador) (1975), Las funciones directivas, pp.15-29, Barcelona: Labor.

Barcia Goyanes, J.J. (1980) (citado por Gutiérrez Rodilla, 1998). "Expresiones y términos incorrectos en las ciencias neurológicas". Medicina Española, 79: 377-382.

CABré, M. Teresa (1999). La terminología: representación y comunicación, Barcelona: Instituto Universitario de Linguiística Aplicada, 381 pp.

Chiavenato, Idalberto (1992). Introducción a la teoría general de la administración (Introducão a teoria geral da administracão, 1976), $3^{\mathrm{a}}$ ed. ( $2^{\mathrm{a}}$ en español), tr. Luis O. Rodríguez Acosta, México: McGraw-Hill, 687 pp.

Dávila Ladrón de Guevara, Carlos (2001). Teorías organizacionales y administración. Enfoque crítico, 2a ed., Bogotá: McGraw-Hill, 317 pp.

Fernández Arena, José Antonio (1969). El proceso administrativo, $3^{\text {a }}$ ed. reformada de la $2^{\mathrm{a}}$ ed., México: Herrero Hermanos Sucesores, 249 pp.

GutiérRez Rodilla, Berta M. (1998). La ciencia empieza en la palabra: análisis e historia del lenguaje científico, Ediciones Península, 381 pp.

GuZmán Valdivia, Isaac (1974). La ciencia de la administración, México: Limusa.

Jiménez CASTro, Wilburg (1965). Introducción al estudio de la teoría administrativa, $2^{a}$ ed., México: Fondo de Cultura Económica, 340 pp.

KAZMIER, Leonard, J. (1974). Principles of Management: A Programmed-Instructional Approach, $3^{\mathrm{a}}$ ed., New York: McGraw-Hill Book Company, 519 pp. 
KliKsberg, Bernardo (1990). El pensamiento organizativo: de los dogmas a un nuevo paradigma organizacional, $12^{\mathrm{a}} \mathrm{ed}$., Buenos Aires: Tesis, $457 \mathrm{pp}$.

Koontz, Harold y Cyril O’Donnell (1955). Principles of Management: An Analysis of Managerial Functions, New York: McGraw-Hill Book Company, $664 \mathrm{pp}$.

(1959). Principles of Management: An Analysis of Managerial Functions, 2a. ed., New York: McGraw-Hill Book Company, 664 pp.

(1961). Principios de dirección de empresa: un análisis de las funciones directivas, $2^{\mathrm{a}}$ ed., trad. Rafael Cremades Cepa, Madrid: McGraw-Hill y Ediciones del Castillo, $741 \mathrm{pp}$.

(1968). Principles of Management: An Analysis of Managerial Functions, $4^{\text {a }}$ ed., New York: McGraw-Hill Book Company, 822 pp.

(1970). Curso de administración moderna: un análisis de las funciones de la administración, $3^{\mathrm{a}}$ ed., trad. y adaptación de Ignacio Pérez Salgado, México: McGraw-Hill, 702 pp.

(1972). Principles of Management: An Analysis of Managerial Functions, $5^{\text {a }}$ ed., New York: McGraw-Hill Book Company, 748 pp.

(1976). Management: A Systems and Contingency Analysis of Managerial Functions, $6^{a}$ ed., New York: McGraw-Hill Book Company.

(1977). Curso de administración moderna: un análisis de las funciones de la administración, $5^{\mathrm{a}}$ ed., trad. Giovanni Ciardelli Fadul, Gabriel Ochoa Acevedo, Jaime Rodríguez Rodríguez y Atala Caamaño de Burgos, México: McGraw-Hill, 785 pp.

(1979). Curso de administración moderna: un análisis de sistemas y contingencias de las funciones administrativas, $6^{\mathrm{a}}$ ed., trad. Jaime Gómez Mont Araiza, México: McGraw-Hill, 914 pp.

Koontz, Harold, Cyril O'Donnell y Heinz WeiHrich (1980). Management, $7^{\mathrm{a}}$ ed., international student edition, Tokyo: McGraw-Hill, 832 pp. 
Koontz, Harold y Heinz WeIHRICH (1994). Administración: una perspectiva global, $10^{a}$ ed., trad. Julio Coro Pando, México: McGraw-Hill, 745 pp.

(1998). Administración: una perspectiva global, $11^{\mathrm{a}}$ ed., trad. Enrique Mercado González, México: McGraw-Hill, 796 pp.

(2003). Administración: una perspectiva global, $12^{\mathrm{a}}$ ed., trad. Enrique Palos Báez y Francisco Javier Dávila Martínez, México: McGraw-Hill, $804 \mathrm{pp}$.

LitTerer, Joseph A. (1984). Una Introducción a la administración, México: Compañía Editorial Continental, 595 pp.

Mc Gregor, Douglas (1985). El aspecto humano de las empresas (The Human

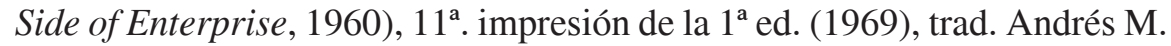
Mateo, México: Diana, 237 pp.

Mouzelis, Nicos P. (1973a). Organización y burocracia. Un análisis de las teorías modernas sobre organizaciones sociales (Organisation and Bureaucracy. An Analysis of Modern Theories), trad. Joan Prats, Barcelona: Península, $237 \mathrm{pp}$.

(1973b). Organisation and Bureaucracy. An Analysis of Modern Theories, quinta reimpresión de la primera edición en pasta suave (1969), Chicago: Aldine Publishing Company, 230 pp.

Nicol, Eduardo (1984). Los principios de la ciencia, México: Fondo de Cultura Económica, $511 \mathrm{pp}$.

Reyes Ponce, Agustín (1985). Administración de empresas. Teoría y práctica. Primera y segunda partes, 22 ${ }^{\mathrm{a}}$ reimpresión de la $1^{\mathrm{a}}$ ed. (1968), México: Limusa, 392 pp.

Ricoeur, Paul (2005). Sobre la traducción, trad. y prólogo Patricia Wilson, Buenos Aires: Paidos, 75 pp.

Silva Camarena, Juan Manuel (2004). "La ciencia: un asunto de palabras", en Contaduría y administración, No 212, enero-marzo, 2004, pp. 5-24. 
SCARon, Pedro (1985). "Advertencia del traductor", en Marx, Karl, El capital. Crítica de la economía política, Tomo I, Vol. 1, Libro primero: El proceso de producción del capital, $15^{\mathrm{a}}$ ed. en español, traducción, advertencia y notas de Pedro Scaron, México: Siglo veintiuno, 381 pp.

Simon, Herbert A. (1997). Administrative Behavior. A Study of Decision-Making Processes in Administrative Organizations, $4^{\mathrm{a}}$ ed., actualizada y aumentada por el autor, $368 \mathrm{pp}$.

Terry, George R. (1971). Principios de administración, $1^{\mathrm{a}}$ ed. en español de la $5^{\mathrm{a}}$ ed. en inglés México: Compañía Editorial Continental, 878 pp.

(1972). Principles of Management, $6^{\text {a }}$ ed., $5^{\text {a }}$ impresión (junio, 1974), Homewood: Richard D. Irwin, 703 pp.

y Stephen G. Franklin (1985). Principios de administración, $4^{\mathrm{a}}$ ed. en español de la $8^{a}$ en inglés, México, Compañía Editorial Continental, $747 \mathrm{pp}$.

WÜSTER, Eugen (1998). Introducción a la teoría general de la terminología y a la lexicografía terminológica, Barcelona: Institut Universitari de Lingüística Aplicada, Universitat Pompeu Fabra, 227 pp. 